\title{
University language policy in Estonia and Catalonia. Is there a north-south divide in European higher education?
}

\begin{abstract}
Within the context of the internationalisation of higher education, language matters have become increasingly prominent for universities across a wide variety of contexts. This has made the higher education domain an attractive site for applied linguists and sociolinguists to investigate in close detail. One relatively consolidated idea is that contexts in which English has made further incursions in universities are more internationalised than those settings where English has penetrated to a lesser extent. In line with that, a supposed north-south divide in European higher education has been conceived of, with universities in the north leading in terms of internationalisation efforts, while those in the south lag behind. In this article, I problematise this idea and suggest instead that a narrower and more focused contrastive analysis between language ecologies across different countries and contexts might be more useful. In doing that, we can thus avoid the dangers of binarism and lumping that can come associated to holding preconceived geographical borders. In particular, the comparative analysis proposed here allows us to highlight two key issues that seem to be highly pressing in present-day higher education domains: the language-ideological and the socio-economic. I build the argument in the paper by utilising empirical material from Estonia and Catalonia, two contexts that have been at the centre of my own work in recent years.
\end{abstract}

Keywords: Language policy, higher education, internationalisation, Estonia, Catalonia.

\section{Introduction}

One relatively wide-spread idea about the internationalisation of higher education and its connection to the English language is that, bluntly put, more English translates into more internationalisation. This, of course, has been problematised already, but somehow, the idea persists. More narrowly, a common-sense conclusion derived from this widespread idea is that the more a university system incorporates English, particularly (but not exclusively) for teaching purposes, the more it can be considered an internationalised environment. From this conclusion, it follows that universities in the north of Europe are more internationalised than those in the south, with the

Josep Soler, Department of English, Stockholm University, SE-106 91 Stockholm, Sweden, josep.soler@english.su.se 
former having more institutions offering more English-taught programmes than those in the latter (e.g. Wächter/Maiworm 2014). Such an oversimplification, however, may lead scholars to think that because institutions and their members operate in very distinct sociolinguistic realities, the issues that they may face are essentially different as well. Partly, that can certainly be true. However, it is also possible to argue that if we scratch a bit deeper than the surface level provided by numbers, we may see that regardless of geographical location, institutions and their members are dealing with very similar concerns, responding through language policy developments to issues connected with ideological and economic matters. This is the argument that I shall illustrate in this article, utilising empirical material from the higher education contexts of Estonia and Catalonia.

Estonia and Catalonia are not a frequent pairing in comparative sociolinguistics, although some authors have in the past analysed in some detail their differences and similarities from that very same point of view (e.g. Branchadell 2011; Laitin 1992; Shafir 1995; Skerrett 2010; Soler 2013). The rationale behind looking at the two cases comparatively rests mainly on historical, socio-political, and sociolinguistic factors. During an extended period in the 20th century, the two nations found themselves dominated by authoritarian regimes (Francoism, 1939-1975, and the Soviet totalitarianism, 19401991, respectively). In the course of those decades, the social, demographic and sociolinguistic landscapes of the two contexts were substantially modified by the arrival of migrant workers who settled in the growing industrial areas in the urban centres of the two places (Branchadell 2011). Moreover, those arrived during the period were speakers of the dominant language, Spanish and Russian respectively, who would in most cases be able to lead their lives without an important need to become proficient in the local language. Nevertheless, and this is an important difference, the influx of newcomers in Estonia stopped and even receded in the late 1980s and 1990s. In Catalonia, by contrast, the number of residents of migrant origin has continued to grow, almost exponentially, over the past decade in particular. It is therefore possible to state that Catalonia features a socially and linguistically more heterogeneous society than Estonia, despite the fact that the latest Population and Housing Census (Statistics Estonia 2011) has documented a total number of 157 different languages spoken presently in Estonia. In 1998, only $2.4 \%$ of the population in Catalonia were of foreign origin (i.e. from outside Spain); by 2013, that percentage had increased up to $14.6 \%$ (Idescat n.d.).

In addition to historical and socio-demographic factors, another similarity between Estonia and Catalonia (particularly important for the purposes of this article) is the specific kind of language contact situation that exists in the two contexts: a medium-sized language (Catalan and Estonian, respectively) coexisting with a more widely spoken language (Spanish and Russian, respectively) in a position of contested power relations. Such contested power relations are not the exact same ones in Estonia as in Catalonia, but again, similarities can be observed, especially from the point of view of the institutional efforts in order to keep reinforcing the societal position of 
the medium-sized language in both contexts. Even after the socio-political changes referred to above, dating back several decades, institutions in both Estonia and Catalonia are busy making sure speakers' linguistic rights are preserved, and that the languages continue to be employed in public domains as resources for social cohesion.

The label 'medium-sized language' might not be familiar to all readers. It is, however, a concept that has been theorised for some time now by researchers at the University of Barcelona (see e. g. Bastardas et al. 2018; Boix-Fuster 2015; Vila 2013). The main theoretical thrust behind this concept is to try to capture the sociolinguistic challenges facing language communities that fall in-between the categories of 'majority' and 'minority' languages. Medium-sized languages are primarily conceived of as languages in post-industrial, technologically advanced societies, many of which enjoy the quality of statehood (i. e. they are state-level, national languages). These languages have a strong degree of sociolinguistic vitality; in most domains, they are viable languages, likely to continue being transmitted from generation to generation. However, in the context of globalisation, increased transnational connections and global flows of goods, people, and information, societies with medium-sized languages find themselves facing similar concerns. Among others, such shared issues for speakers of medium-sized languages include the need to acquire languages of wider communicative reach in a more systematic way, making more active use of their plurilingual repertoire than it might have been the case in the past. In some domains in particular, the more intense contact with languages of wider communication might lead to questioning the long-term sustainability of the medium-sized language in that context.

One specific domain that has been identified as particularly sensitive for the long-term presence of medium-sized languages is higher education (Vila/Bretxa 2015). Indeed, if we look at it in strict quantitative terms, only a handful of medium-sized languages around the world are used in the context of higher education, the majority of them in Europe, and mostly for teaching and learning purposes at lesser advanced levels (i. e. at undergraduate rather than graduate and postgraduate levels) (Laponce 2006). With this in mind, the question that follows almost inevitably is: will these medium-sized languages that have made it up to the level of higher education keep their presence in that domain, or will they eventually 'quit the club', as Vila (2015) puts it. In what follows, I take Estonia and Catalonia as illustrative cases of two medium-sized language communities and analyse some current issues in connection to their languages in the domain of higher education. In building my argument, I shall also tackle the perceived north-south divide in European higher education and the debates around the internationalisation of higher education. I shall show that perhaps such divide is less clear cut than is sometimes presented and that, whether in the north or in the south of Europe, higher education systems are shot through by issues of very similar nature, frequently with concerns that have to do with both identity and economic matters. 


\section{Language, internationalisation, and higher education}

In the context of universities becoming increasingly international, as higher education institutions turn into internationally competitive and more attractive study and workplaces for a wider variety of students and staff, questions about language are increasingly more relevant. Indeed, language matters are laden by a multiple number of factors, including (but not limited to) practical, political, and socio-economic ones. At a practical level, questions about language in internationalising university environments typically are connected to issues of teaching and learning (if teaching takes place in an L2 or foreign language, debates emerge as to what best strategies should be followed to ensure that students' learning process is not hampered). At a political level, in the Nordic countries in particular, concerns are normally aired in connection to the notion of domain loss, together with the idea that universities should continue to uphold their national responsibilities and make sure that the respective national language is used for meaningful purposes in the higher education domain. Finally, at a socio-economic level, universities, and particularly university officials, may worry about the sustainability of their budget bases, and in that respect, they may think of alternative ways of expanding their sources of income for example via the introduction of English-taught programmes (ETPs) for fee-paying students.

With the above in mind, it is not surprising that, in recent times, universities have become attractive research sites for sociolinguists and applied linguists. Plenty of studies have been conducted in the past few years in connection to the three strands broadly outlined above: the practical, the political, and the socio-economic dimensions of higher education. The relevance of language, and language-connected issues, in all three areas has been more than attested by research with contributions from a wide variety of contexts. From all three perspectives, one particular sociolinguistic dynamic that has centred the focus of analyses is the increasing incorporation of the English language in more and more higher education systems outside Anglophone countries, and the effects that this has had at a national/local level. Discussions about the Englishization of higher education are nowadays abundant (e.g. Hultgren et al. 2014). However, the idea that the higher education domain deserved to be analysed from a sociolinguistic and language-political perspective is not entirely new. The same holds true for the focus on English. Ammon's (2001) collection of essays is perhaps one of the earliest volumes on this topic, attesting that already at the turn of the century, in the context of a then growing literature on language and globalisation (e.g. Maurais/Morris 2003), universities were seen as a key site where issues of sociolinguistic nature, and specifically the impact of the English language, should be analysed in greater detail.

Indeed, in the context of the post-national university (Bull 2004; Haberland/ Mortensen 2012) and in non-Anglophone settings, English seems to be behind many 
of the debates of all kinds of nature (practical, political, socio-economic) in the higher education domain. On the one hand, there is the empirical reality that more universities in more countries are actively engaged in expanding the number of ETPs that they offer. Wächter and Maiworm's 2014 report indicated a rise in the number of MA ETPs offered in European higher education from N=2389 in 2007 to $\mathrm{N}=8089$ in 2014 (and only $\mathrm{N}=725$ in 2003). Even with a methodological note of warning (more institutions were covered over the years in which the different reports were elaborated), the growth in absolute numbers of ETPs at the MA level is certainly without doubt. On the other hand, we see in parallel a development of language-ideological debates and controversies that emerge in higher education systems across a variety of countries, from Italy (Santulli 2015; Pulcini/Campagna 2015), to the Netherlands (de Rechtspraak 2018), to Latvia (The Baltic Times 2018). It might be far-fetched to suggest that English is the single or even the main cause of these debates, but it certainly is possible to trace a connection between a greater use of the language for different functions at universities and the emergence of language-related tensions and ambiguities in the context of higher education.

Needless to say, thinking about higher education as one single, monolithic domain, would be misguided. Within universities, there is an ample range of contexts where different languages may come into play in complementary ways. In that regard, Hamel (2008) outlines three different spheres with a number of different activities and sub-activities within these spheres in the context of higher education (see also Darquennes/du Plessis/Soler 2020). Depending on the context, each of these activities can be carried out more frequently in one language or another. In Hamel's model, the three main spheres in higher education consist of (a) scientific research/knowledge production, (b) diffusion and communication/knowledge consumption, and (c) scientific training. Haberland (2014) adds a fourth dimension to Hamel's model: administration, which is by now increasingly seen as another key part of universities' language ecologies in the context of higher education internationalisation (Llurda et al. 2014; Siiner 2016). All these different spheres are context-dependent and they may entail different linguistic practices and ideologies (Haberland 2014: 253-254). When conducting research, for example, everyday conversations in laboratories and departments, discussing project developments and so on can be certainly done in languages other than English, in non-Anglophone universities (Bretxa et al. 2016). Scientific communication (diffusion) and knowledge consumption is increasingly more dominated by English, a trend that is discipline specific (Kuteeva/Airey 2014: 539) and more recent in the humanities than in natural sciences. In terms of scientific training (i.e. education), again there is field-specific variation, as well as degree level variability, with more English being used in the hard sciences and in graduate level courses than in the humanities and in undergraduate degrees (Wächter/Maiworm 2014).

So, there is a variety of situations and contexts and there is a variability of languages used in them that is contingent on a great number of factors. With this in mind, it is not surprising that university officials and administrators may find it hard 
to address current sociolinguistic challenges at universities. In the Nordic countries, the approach taken from a language policy point of view has been characterised by the strategy known as 'parallel language use' (Linn 2010), a strategy that in principle entails that languages can be used in parallel in all the different contexts of the higher education domain. Inherently vague and ambiguous in nature, this approach has been already problematized (e.g. Fabricius et al. 2017; Kuteeva 2014). Indeed, in the context of Swedish higher education, Hult/Källkvist (2015) show that 'parallel language use' may be discursively shaped differently depending on the scale in which it is projected: local/national versus global. In the former, 'parallel language use' might frequently mean 'more Swedish', whereas in the latter, it might mean 'more English'. Nevertheless, this is the approach that, formally, the vast majority of universities in Sweden have taken when developing their specific language policy documents (Björkman 2014).

\section{Estonia and Catalonia: language policies and socio-economic factors in higher education}

With the above in mind, how do institutions of higher education in Estonia and Catalonia address language-related questions? How are language matters framed in university policy documents in the two contexts? How is language made relevant against the background of socio-economic concerns? In what follows, I tackle these questions by revisiting some of my own work on these topics, adding some original nuances to the arguments I have already presented elsewhere, in particular in connection to the socio-economic dimension. I shall, however, restrict myself to the most relevant elements of my analyses for the sake of the argument I construct in the article. Thus, I spare the reader of the methodological details of the work I draw on (mostly revolving around ethnographic and discursive approaches to language policy analysis); these are, nevertheless, readily available to anyone interested in these more intricate details in my recent work (see, in particular, Soler [2019], for the Estonian case, and Soler/ Gallego-Balsà [2019], for the Catalan case).

Let us start with university language policy documents in the first place. With a combination of content and thematic analysis (Braun/Clarke 2006; Hsieh/Shannon 2005), the main themes that emerge from the language policy documents in Estonian and Catalan higher education are not drastically different (see also Soler et al. 2018; Soler 2019: chapter 2; Soler/Gallego-Balsà 2019: chapter 3). Table 1 below summarises the list of the four key themes from each of the two contexts. 
Table 1: Main themes from university language policy documents in Estonia and Catalonia

\begin{tabular}{ll}
\hline Estonia & Catalonia \\
\hline $\begin{array}{l}\text { Theme 1: Estonian needs to be protected, pro- } \\
\text { moted, and developed. }\end{array}$ & $\begin{array}{l}\text { Theme 1: Catalan is the own and official lan- } \\
\text { guage of Catalonia and of Catalan universities. It } \\
\text { deserves to be given priority. }\end{array}$ \\
$\begin{array}{ll}\text { Theme 2: Competitiveness and internationaliza- } \\
\text { tion demand an increase of 'foreign languages'. }\end{array}$ & $\begin{array}{l}\text { Theme 2: Spanish as a right: Individually, speak- } \\
\text { ers have the right to use and to be understood } \\
\text { in Spanish, which is also an official language in } \\
\text { Catalonia. }\end{array}$ \\
$\begin{array}{ll}\text { Theme 3: English as a resource: speakers should } \\
\text { have more access to it and enhance their compe- }\end{array}$ \\
$\begin{array}{ll}\text { Theme 3: English as a resource: key in achieving } \\
\text { gheals of internationalization and enhancing } \\
\text { Theme 4: 'English is not enough': English should } \\
\text { coexist with other languages. }\end{array}$ & $\begin{array}{l}\text { Theme 4: Multilingualism: the ultimate goal is } \\
\text { to attain a balance between the different lan- } \\
\text { guages, functionally distributed at the university. }\end{array}$ \\
&
\end{tabular}

In other words, if we take the most relevant themes that can be extracted from a set of policy documents as an indication of the underlying narrative that is presented in them (Prior 2015), we can see that the narrative that frames language-related matters at the higher education domain in the two contexts follows a rather similar logic. Indeed, in both Estonia and Catalonia, priority is given to the idea that the national/ local language deserves special attention within universities, a space in which it might require to be protected, promoted, and developed (Theme 1). In both settings we see an acknowledgement of the fact that a degree of engagement with the English language is nowadays unescapable, so English is seen as a resource of chief importance both institutionally and individually (Theme 3). In addition to English, however, the language policy documents in both settings emphasise the notion that multilingualism is the ideal scenario that should be aimed at (Theme 4).

Of course, differences can be noted as well. For example, the way English is framed shows a degree of nuances: it appears as a more 'foreign' element in Estonia than in Catalonia, where it is conceived as an element of diversity in situ. Another noticeable difference between the two contexts is with regards to the attention paid to the other major societal language in each context, namely Spanish (in Catalonia) and Russian (in Estonia). As seen, Catalan university policy documents do acknowledge the importance of Spanish, mainly in connection to the idea that speakers have the right to use and to be understood in the language in all contexts within higher education (Theme 2). In Estonia, by contrast, Russian is virtually erased from university policy documents, a move by policymakers that would seem to mirror the national level language policy, with a marked Estonian monolingual overtone. Instead, the more euphemistic label 'foreign language(s)' is frequently used in the Estonian documents, a label that might in theory encompass any given foreign language, but much like Finnish higher education language policy, it tends to be used in order not to refer 
explicitly to English all the time (Saarinen 2012; for actual examples illustrating each of the themes and further details in support of these claims, see Soler 2019).

The key message from the similarity between the language policy narratives in the two contexts is that, despite some nuances, the concerns policymakers in both settings seem to share are very close: the idea that the national/local language deserves a degree of protection, the inescapability of the English language, and the desired goal of multilingualism. This is despite the fact that Estonia and Catalonia are geographically apart, with different degrees of incorporation of the English language in their higher education systems (especially for teaching purposes). So, despite these differences, we see rather similar language-ideological concerns at the policy level. This is the first argument to question the north-south divide in European higher education.

Another factor that brings Estonia and Catalonia together is the socio-economic dimension and the impact it has on language management strategies at the university level. In both cases, we see socio-economic factors that trigger language-related debates that move clearly into language management strategies within the higher education domain. Let us start with Estonia first. Since 2011-2012, there has been a clear and steady trend of a decrease in the total number of students enrolled at universities, a reduction of as many as 20,000 students in total, from 67,000 in 2012 to 47,000 in 2018 (Klaas-Lang 2018). Coupled with a national higher education reform of 2013 (one of whose prerogatives was to abolish university fees for students registered in state-funded study places), university officials and stakeholders began to worry about the long-term sustainability of Estonian-medium higher education. The 2013 reform enabled the possibility for universities to charge registration fees for those programmes taught in a language other than Estonian, notably English. In that context, it was perhaps not a coincidence that the late rector of the University of Tartu, Professor Volli Kalm, publicly wondered about how sustainable Estonian-medium higher education would be in the future. At a leadership conference in Pärnu, he was quoted with the following statement:

\footnotetext{
"The difficult questions regarding the future of Estonian higher education are tied to the competitiveness of Estonian higher education compared to English higher education. Master's and doctoral studies are inevitably becoming more English-based. Students will increasingly go abroad for niche disciplines... We are often unaware of the price of preserving Estonian-language higher education" (Kalm 2012).
}

This quickly sparked a number of responses in different media outlets, some in support of Kalm's view, but many more critical of it. To tackle those criticisms, Kalm was compelled to issue another statement, explaining himself better and saying that while it is true that supporting higher education in Estonian is not inexpensive, it is also a responsibility that the country's universities, and particularly the University of Tartu, cannot escape from (see Soler/Vihman [2018] for a more detailed analysis of this specific language-ideological debate). 
In short, we see clearly how societal concerns, combined with economic matters, trickle down into language-related issues, a conflict of non-linguistic interests between different stakeholders in a given language management situation, something already noted in the language planning literature for some time now (e.g. Jernudd/ Neustupny 1987; Neustupny 1983). We can see how language-ideological positions become malleable and articulate (implicitly, but perhaps also more easily) societal, demographic, and economic concerns. In the case of Catalonia, we see how economic measures are both channelled via language management strategies and, at the same time, have an impact on language issues at universities. In this case, the trigger was not a decrease in the number of students enrolled at higher education institutions, but a reduction of the public funding for universities starting in 2010. That year, the growing trend of public spending on Catalan universities was interrupted at just above 700 million euros, and it went down to slightly over 600 million euros in 2014-2015, at which point the decreasing trend was stopped and slightly reverted (see http:// universitatsirecerca.gencat.cat).

Just like in Estonia, higher education reforms also took place in Catalonia at the same time that the budgetary restrictions were being implemented, and much like in Estonia, these reforms came together with language-related concerns, in the case of Catalonia perhaps even more explicitly. In fact, even before the 2010 budgetary restrictions, universities had already started drafting their individual language policy documents. By that time, a public discussion began to consolidate itself around the role of universities in ensuring that future generations in Catalonia would be fluent in a 'third' language (meaning, almost invariably, English). Initially, a policy reform was passed so that universities were prompted to recommend their graduates in all disciplines that, by the time they would complete their studies, they would possess a B2 level of the CEFR in a 'third language'. In 2014, this recommendation became legally binding and economically transcendental: the requirement became part of the law that regulates the fiscal, administrative, and financial measures of Catalonia's public sector (Article 211 of Law 2/2014 of 27 January). Needless to say, the reform did not go down well with university administrators, who saw yet another obstacle imposed on them in order to access the already decreasing available funding.

After some degree of confrontation between university and government officials, an agreement was reached in May 2018, and the Catalan parliament passed an amendment to the 2014 law so that the requirement for students to possess a B2 level in a 'third' language was postponed for another four years. In theory, those students who began their university degrees in the academic year 2018-2019 will have to possess such a language certificate by the time they graduate (by 2021-2022). In reality, it remains largely unclear how strictly universities will be able to enforce such a regulation, unless the syllabi of all the programmes in all the disciplines in all the public universities in Catalonia are modified to include some language proficiency requirements. Without the proper resources to put in place these changes, it does not seem that higher education officials in Catalonia are likely to go down that route, 
and without those changes, it seems legally impossible to prevent a student who has completed all the credit course requirements not to be awarded their university degree just because they do not have a B2 certificate in a 'third' language. In sum, it seems very likely that the requirement will simply be postponed ad infinitum, or at least until another policy reform is put in place in order to bring it back to a recommendation (for more details on language policy in Catalan higher education see also Pons-Parera 2015; Vila 2015; Soler/Gallego-Balsà 2019).

All in all, in addition to the narratives underlying university policy documents in Estonia and Catalonia, another important similarity can be brought up for discussion: the socio-economic dimension and its impact on language management strategies. Although prompted by apparently different concerns (a demographic decrease in number of students, in the case of Estonia, and a decrease in the public funding available for universities, in the case of Catalonia), we see how language policy initiatives become a tool for public officials to gear decisions in a given direction and to manage a given context, in this case the domain of higher education, with specific agendas in mind. In the next and final section of the article, I elaborate on this further, linking it to the implications it has in connection to how we conceptualise higher education language policy, specifically with regards to the so-called north-south divide in European higher education.

\section{Conclusions}

At the start of the article, I set out to problematise the often taken-for-granted existence of a north-south divide in the internationalisation of higher education in Europe. I hope the above section has made it clear that such a divide is more perceived than real. Indeed, while at first sight Estonia and Catalonia would appear to show very distinct higher education settings (particularly in connection to the percentage of English-taught programmes), when we look beyond the numeric and statistical overviews, we start to notice important similarities. Readers interested in more detailed, in-depth analyses of the two cases should find enough relevant material in Soler (2019) and Soler/Gallego-Balsà (2019). In this article, I have shown that some of the similarities between the two cases have to do with two dimensions that are crucial in any sociolinguistic context, but particularly more so in settings with medium-sized languages. These dimensions are the language-ideological, on the one hand, and the socio-economic, on the other. For all the numeric differences, Estonian and Catalan higher education stakeholders are concerned with the sustainability of their own language at the university domain, even if there is an acknowledgement of the inescapability of English, and a shared desire of multilingualism as a final goal. In both settings, socio-economic concerns are pressing (decreasing number of students, on one hand, and decrease in public spending on universities, on the other), and these concerns 
materialise themselves and are channelled through language policy developments. With this in mind, statements such as the following seem to go a bit too far in their assessment of the reality of higher education internationalisation across different geographical areas in Europe:

"There remain huge differences between individual countries, especially in the form of a NorthSouth divide. As in our earlier reports, the Nordic countries and the Netherlands are the leading providers [of English-taught programmes]. The runners-up are the Baltic States. Southern European countries are still largely “abstentious”” (Wächter/Maiworm 2014: n.p.).

There certainly is an element of truth in this depiction of the current situation in European higher education, but it is also equally important to remind ourselves that "while estimates on EMI [English-medium instruction] are useful in their own right, they often conceal a highly complex and linguistically diverse reality at internationalised universities" (Hultgren et al. 2015: 5). Not only that. I would add that such representations of clear-cut differences between geographical regions carries two important dangers: a danger of binarism and a danger of lumping. Translated into the domain of higher education and the supposed geographical divide, binarism implies the notion that just because two institutions are located in distinct geopolitical areas, they will by default show different realities. Lumping, on the other hand, is the reverse process: the notion that whenever two institutions share the same geopolitical location, they will, also by default, share very similar realities. These two conceptual processes may add to the difficulty of finding similarities across institutions in preconceived borders and of looking for differences between institutions within the same areas.

At least since the foundational work of Einar Haugen (1972), we know of the importance of examining and understanding linguistic ecologies in their locally situated terms. This seems particularly important in order to better grasp the kind of language contact situations in present-day globalised times, and to understand the competition, or indeed the conflict, between different types of languages. In that regard, Vila (2015) has argued that environments with medium-sized languages are highly sensitive to societal changes and developments, and this seems particularly true for the domain of higher education. Certainly, in a relatively very short period of time, the domain of higher education in medium-sized language contexts, especially in Europe, has become increasingly complex and sociolinguistically challenging. Some of the challenges of such contexts have been highlighted in this article, and these pertain to: (a) the centrality of language-ideological concerns, and (b) the prevalence of socio-economic matters and the impact they have on language and language policy developments. On both levels, the language-ideological and the socio-economic, it seems clear that language may easily lend itself as an element that can be manipulated by specific stakeholders in a given context in order to advance specific agendas.

In sum, in addition to looking at general trends and the overall picture offered by large-scale statistical reports, certainly valuable and something that should continue to be conducted, we should also not lose sight of the importance of narrowing down 
our analyses into specific language configurations, and try to point out which agents are behind what kind of language policy initiatives and for what purposes. The above analysis has hopefully hinted at the usefulness of taking such an angle, particularly from the point of view of the socio-economic dimension of higher education institutions. With that in mind, it seems crucial to continue carrying out cross-country and cross-institutional contrastive studies of the language policy developments in particular domains, in this case, in higher education. Language-ideological and socio-economic concerns are likely to continue to act as powerful motors of language-related issues in contemporary times, and researchers will do well to continue focusing on them.

Acknowledgements: This paper was developed and written while I was holding a Visiting Junior Professor position at RECLAS (Research Collegium for Language in Changing Society) of the University of Jyväskylä, Finland, in autumn 2019. I am deeply grateful for the support received from the institution.

\section{References}

Bastardas, Albert/Boix-Fuster, Emili/Torrens-Guerrini, Rosa M. (eds.) (2018): El català, llenua mitjana d'Europa. Multilingüisme, globalització i sostenibilitat lingüística. Barcelona: Octaedro.

Björkman, Beyza (2014): Language ideology or language practice? An analysis of language policy documents at Swedish universities. In: Multilingua 33, 3-4, 335-363.

Boix-Fuster, Emili (ed.) (2015): Urban diversities and language policies in medium-sized linguistic communities. Bristol: Multilingual Matters.

Branchadell, Albert (2011): Assessing language policy. The treatment of Russian in Estonia and of Spanish in Catalonia. In: Revista de Llengua we Dret 55, 123-150.

Braun, Virginia/Clarke, Victoria (2006): Using thematic analysis in psychology. In: Qualitative Research in Psychology 3, 2, 77-101.

Bretxa, Vanessa/Comajoan, Llorenç/Vila, F. Xavier (2016): Is science really English monoglot? Language practices at a university research park in Barcelona. In: Language Problems and Language Planning 40, 1, 47-68.

Bull, Tove. 2004. Dagens og gårdagens akademiske lingua franca. Eit historisk tilbakeblikk og eit globalt utsyn [The academic lingua franca of today and yesterday. A historical retrospect and a global review]. In: Simonsen, Dag F. (ed.): Språk i kunnskapssamfunnet. Engelsk - elitenes nye latin? [Language in the knowledge society. English - the new Latin of the elites?]. Oslo: Gyldendal Norsk Forlag, 35- 45.

De Rechtspraak (2018): Geen verbod op Engels als voertaal bij universiteiten. Available online: https://www.rechtspraak.nl/Organisatie-en-contact/Organisatie/Rechtbanken/RechtbankMidden-Nederland/Nieuws/Paginas/Geen-verbod-op-Engels-als-voertaal-bij-universiteiten. aspx (Last accessed 31 October 2019).

Fabricius, Anne/Mortensen, Janus/Haberland, Hartmut (2017): The lure of internationalization: Paradoxical discourses of transnational student mobility, linguistic diversity and cross-cultural exchange. In: Higher Education 73, 4, 577-595. 
Haberland, Hartmut (2014): English from above and below, and from outside. In: Hultgren, Anna Kristina/Gregersen, Frans/Thogersen, Jacob (eds.): English in Nordic universities: Ideologies and practices. Amsterdam: John Benjamins, 251-263.

Haberland, Hartmut/Mortensen, Janus (eds.) (2012): Language and the international university. [Special Issue, International Journal of the Sociology of Language 216]. Berlin: De Gruyter.

Hamel, Rainer (2008): Les langues de la science: Vers un modèle de diglossie gérable. In: Maurais, Jacques/Dumont, Pierre/Klinkenberg, Jean-Marie/Maurer, Bruno/Chardenet, Patrick (eds.): L'avenir du français. Paris: AUF, Editions des archives contemporaines, 87-94.

Haugen, Einar (1972): The ecology of language. Stanford: Stanford University Press.

Hsieh, Hsiu-Fang/Shannon, Sarah E. (2005): Three approaches to qualitative content analysis. In: Qualitative Health Research 15, 9, 1277-1288.

Hult, Francis/Källkvist, Marie (2016): Global flows in local language planning: articulating parallel language use in Swedish university policies. In: Current Issues in Language Planning 17, 1, 56-71.

Hultgren, Anna Kristina/Thøgersen, Jacob (2014): Englishization of Nordic universities. Policy and practice - a disconnect. In: Language Problems and Language Planning 38, 3, 247-264.

Hultgren, Anna Kristina (2015): English as an international language of science and its effect on Nordic terminology: the view of scientists. In: Linn, Andrew/Bermel, Neil/Ferguson, Gibson (eds.): Attitudes towards English in Europe. Berlin: De Gruyter Mouton, 139-164.

Idescat (n.d.)/Institut d’Estadística de Catalunya. Available online www.idescat.cat (Last accessed 31 October 2019)

Jernudd, Björn/Neustupny, Jirí (1987): Language planning - For whom? In: Proceedings of the International Colloquium on Language Planning (Ottawa, May 25-29 1986), 70-84.

Kalm, Volli (2012): Ahistavad keelehirmud [Oppressive language fears]. In: Postimees. Arvamus. 25. 10. 2012.

Klaas-Lang, Birute (2018): Language policy and the sustainability of Estonian in higher education. Paper presented at the symposium: Internationalisation of Universities and the National Language. KU Leuven, Belgium, 4th May 2018.

Kuteeva, Maria (2014): The parallel language use of Swedish and English: the question of 'nativeness' in university policies and practices. In: Journal of Multilingual and Multicultural Development 35, 4, 332-344.

Kuteeva, Maria/Airey, John (2014): Disciplinary differences in the use of English in higher education: Reflections on recent language policy developments. In: Higher Education 67, 5, 533-549.

Laitin, David (1992): Language normalisation in Estonia and Catalonia. In: Journal of Baltic Studies 23, 2, 149-166.

Laponce, Jean (2006): Loi de Babel et autres régularités des rapports entre langue et politique. Lévis, Québec: Presses de l'Université de Montreal.

Linn, Andrew (2010): Can parallelingualism save Norwegian from extinction? In: Multilingua 29, 3-4, 289-305.

Llurda, Enric/Cots, Josep M./Armengol, Lourdes (2014): Views on multilingualism and internationalisation in higher education: Administrative staff in the spotlight. In: Journal of Multilingual and Multicultural Development 35, 4, 376-391.

Maurais, Jacques/Morris, Michael A. (eds.) (2003): Languages in a globalising world. Cambridge: Cambridge University Press.

Neustupny, Jirí (1983): Towards a paradigm for language planning. In: Language Planning Newsletter 9, 4, 1-6.

Pons-Parera, Eva (2015): The position of Catalan in higher education in Catalonia. In: Vila, F. Xavier/ Bretxa, Vanessa (eds.): Language policy in higher education: The case of medium-sized languages. Bristol: Multilingual Matters, 153-180. 
Prior, Lindsay (2014): Content analysis. In: Leavy, Patricia (ed.): The Oxford handbook of qualitative research. Oxford: Oxford University Press, 359-379.

Pulcini, Virginia/Campagna, Sandra (2015): Internationalisation and the EMI controversy in Italian higher education. In: Dimova, Slobodanka/Hultgren, Anna-Kristina/Jensen, Christian (eds.): English-medium instruction in European higher education. Boston/Berlin: De Gruyter Mouton, 65-87.

Saarinen, Taina (2012): Internationalisation of Finnish higher education - is language and issue? In: International Journal of the Sociology of Language 216, 157-173.

Santulli, Francesca (2015): English in Italian universities: The language policy of PoliMi from theory to practice. In: Dimova, Slobodanka/Hultgren, Anna-Kristina/Jensen, Christian (eds.): English-medium instruction in European higher education. Boston/Berlin: De Gruyter Mouton, 269-290.

Shafir, Gershon (1995): Immigrants and nationalists: Ethnic conflict and accommodation in Catalonia, the Basque Country, Latvia and Estonia, New York: State University of New York Press.

Siiner, Maarja (2016): University administrators as forced language policy agents. An institutional ethnography of parallel language strategy and practices at the University of Copenhagen. In: Current Issues in Language Planning 17, 3-4, 441-458.

Skerrett, Delaney (2010): Language and authoritarianism in the 20th century: The cases of Estonia and Catalonia. In: Estonian Papers in Applied Linguistics 6, 261-276.

Soler, Josep (2013): The anonymity of Catalan and the authenticity of Estonian: two paths for the development of medium-sized languages. In: International Journal of Bilingual Education and Bilingualism 16, 2, 153-163.

Soler, Josep (2019): Language policy and the internationalization of universities. A focus on Estonian higher education. Berlin: De Gruyter Mouton.

Soler, Josep/Gallego-Balsà, Lídia (2019): The sociolinguistics of higher education. Language policy and internationalisation in Catalonia. Basingstoke: Palgrave macmillan.

Soler, Josep/Vihman, Virve-Anneli (2018): Language ideology and language planning in Estonian higher education: Nationalising and globalising discourses. In: Current Issues in Language Planning 19, 1, 22-41.

Statistics Estonia (2011): Population and housing census. Available online http://www.stat.ee/ phc2011 (Last accessed 31 October 2019)

The Baltic Times (2018): Education Ministry proposes that private universities and colleges should not be permitted to teach students in Russian. Available online: https://www.baltictimes. com/education_ministry_proposes_that_private_universities_and_colleges_should_not_be permitted_to_teach_students_in_russian/ (Last accessed 31 October 2019)

Vila, F. Xavier (2015): Language policy in higher education in medium-sized language communities: An introduction. In: Vila, F. Xavier/Bretxa, Vanessa (eds.): Language policy in higher education. The case of medium-sized languages. Bristol: Multilingual Matters, 1-14.

Vila, F. Xavier (2013): Survival and development of language communities. Prospects and challenges. Bristol: Multilingual Matters.

Vila, F. Xavier/Bretxa, Vanessa (eds.) (2015): Language policy in higher education. The case of medium-sized languages. Bristol: Multilingual Matters.

Wächter, Bernd/Maiworm, Friedhelm (eds.) (2014): English-taught programmes in European higher education. The state of play in 2014. Bonn: Lemmens. 